Thaís Gomes Verzi gnassi Si lveira 2 U esl ei Teodoro 2

Maria Valdrinez Campana Lonardoni 2

Ana Lúcia Falavigna Guilherme 2

Max Jean Ornelas de Toledo 2

Miria Ramos 2

Sandra Mara Al essi Aristides Arraes 2

Dennis Armando Bertolini 2

Roberto Palma Spinoza 3

Orlando Carlos Barbosa 4

\section{Aspectos epidemiológicos da leishmaniose tegumentar em área endêmica do Estado do Paraná, Brasil 1}

\author{
Epidemiologic aspects of Cutaneous Leishmaniasis \\ in an endemic area of the state of Paraná, Brazil 1
}

1 Pesquisa financiada pela Fundação Nacional de Saúde, Companhia Mel horamentos Norte do Paraná e Universidade Estadual de Maringá.

2 Departamento de Análises Clínicas, Universidade Estadual de Maringá. Av. Colombo 5790 Maringá, PR, 87020-900, Brasil.

3 Fundação Nacional de Saúde, Distrito de Londrina. Av. São João 500 , Londrina, PR, 86039-270 Brasil.

4 Fundação Nacional de Saúde, Posto Maringá. Av. Centenário 55, Maringá PR, 87050-040, Brasil.
Abstract An epidemiological investigation of cutaneous leishmaniasis (CL) was performed in 1992 and 1993 in an endemic area of Jussara and Terra Boa counties, in the Northern Paraná State. Thestudy covered 684 individuals from a population of approximately 1,400 from six agricultural areas (Fazenda Palmital, Cerâmica Andirá, Fazenda Jussara, Fazenda Lagoa, Destilaria Melhoramentos, and Fazenda Mururê) in Northern Paraná, Brazil. The mean frequency of CL history was $19.9 \%$. The highest frequency was at Fazenda Jussara (40.5\%). Based on the indirect immunofluorescence test, 58 (8.5\%) presented significant titers of anti-Leishmania antibody, 17 (29.3\%) of whom had no history of CL. The Montenegro skin test was applied to 97 individuals with a history of $C L$ and was positive in 80 (82.5\%). During the survey, seven individuals presented lesions, four of which were positive for Leishmania sp.. The strain isolated was identified as Leishmania (Viannia) braziliensis.

Key words Cutaneous Leishmaniasis; Epidemiology; Zoonosis

Resumo Realizou-se em 1992 e 1993 um inquérito epidemiológico para lei shmaniose tegumentar (LT) envolvendo 684 indivíduos de uma população de aproximadamente 1400 pessoas de sei s localidades agrícol as (Fazenda Palmital, Cerâmica Andirá, Fazenda Jussara, Fazenda Lagoa, Destilaria Melhoramentos e Fazenda Mururê) de uma área endêmica nos Municípios de Jussara e Terra Boa, no Norte do Estado do Paraná, Brasil. Do total de 684 indi víduos estudados, 19,9\% tinham história de LT. Ressal ta-se que na Fazenda Jussara ocorreu o mai or percentual de pessoas com história de LT (51/126 ou 40,5\%). Das 684 reações de imunofluorescência indi reta realizadas, 58 (8,5\%) tiveram títulos significativos, e destas, 17 (29,3\%) eram de pessoas sem história de LT. A intradermorreação de Montenegro foi realizada em 97 indi víduos com história de LT, sendo positiva em 80 (82,5\%) deles. No momento do inquérito, sete indivíduos apresentavam lesão característica de LT, e em quatro deles a pesquisa de Leishmania sp. foi positiva. A cepa de Leishmania isolada de um destes indivíduos foi identificada como Leishmania (Viannia) braziliensis.

Palavras-chave Leishmaniose Tegumentar; Epidemiologia; Zoonose 
Introdução

A leishmaniose tegumentar (LT) ocorre em áreas onde há derrubada de matas e colonização recente, mas ultimamente vem sendo verificada também em áreas de colonização antiga (Barretto et al., 1981) onde existem matas residuais ou de segunda formação. A doença abrange desde formas inaparentes, lesões discretas de pele que podem evoluir espontaneamente para cura, ulcerações múltiplas, lesões de mucosas até formas com tendência às metástases e recidivas, de curso lento e tratamento difícil (Coutinho et al., 1981).

A LT é endêmica no Brasil (Coutinho et al., 1981; Guimarães et al., 1983; Grimaldi et al., 1989; FNS, 1993) e também no Norte do Estado do Paraná, onde o número de casos tem sido elevado (Verzignassi et al., 1988; Teodoro et al., 1991; Silveira et al., 1992; 1993). Atingiu proporções epidêmicas nos últimos três anos (Informações pessoais de J. F. Konolsaisen, Secretaria de Estado da Saúde do Paraná, 1995), caracterizando-se como problema de saúde pública neste Estado.

O diagnóstico laboratorial da LT pode ser feito pela pesquisa direta do parasito em material obtido de úlceras, por intradermorreação de Montenegro e pesquisa de anticorpos antiLeishmania. Contudo, na mai oria das vezes, os laboratórios não estão preparados para a realização destes exames, lançando-se mão apenas do diagnóstico clínico nos serviços de assistência médica. Estes fatos têm acarretado a subnotificação da doença, a demora para o início $\mathrm{e}$, conseqüentemente, o prolongamento do tratamento.

O desconhecimento da epidemiologia da LT, na região Noroeste do Estado do Paraná, estimulou a realização de inquérito epidemiológico em uma população, representada na maioria por trabal hadores e seus familiares, residentes em seis propriedades agrícolas da Companhia Melhoramentos Norte do Paraná, situadas nos Municípios de Jussara e Terra Boa, Estado do Paraná, em 1992 e 1993.

\section{Material e métodos}

População humana

A investigação foi realizada com a colaboração voluntária de 684 pessoas, na maioria trabal hadores e seus familiares, residentes em seis propriedades agrícolas da Companhia Melhoramentos Norte do Paraná, de uma população de aproximadamente 1400 pessoas. As proprieda- des situam-se nos Municípios de Jussara eTerra Boa, sendo que, na Fazenda Palmital, foram estudadas 130 pessoas, 47 na Cerâmica Andirá, 126 na Fazenda Jussara, 61 na Fazenda Lagoa, 106 nas Destilarias Melhoramentos e 214 na Fazenda Mururê, totalizando 684 pessoas.

Dos voluntários foram obtidas informações como identificação, localidade de moradia e história presente ou pregressa de LT.

\section{Soros}

Dos indivíduos estudados foi obtida amostra de sangue venoso, cujo soro foi separado, aliquotado e armazenado a - $18^{\circ} \mathrm{C}$ até o uso.

Reação de imunofluorescência indireta para leishmaniose (IFI)

O antígeno foi preparado com a cepa 034 de Leishmania (Viannia) braziliensis conforme Silveira et al. (1990). A reação de IFI para leishmaniose foi realizada conforme Guimarães et al. (1974), utilizando-se conjugado antiimunoglobulina total humana-isotiocianato de fluoresceína (Biolab), padronizado conforme Camargo (1973). Inicialmente realizou-se uma reação qualitativa com os soros diluídos a 1/20 em solução salina tamponada com fosfato (SST ). Os soros que apresentaram-se positivos nesta reação foram então diluídos em SST a partir de $1 / 20$, em razão 2, para a determinação de seu título. Títulos 40 ou superiores foram considerados significativos (Silveira et al., 1990).

Intradermorreação de Montenegro (IDR)

A IDR de Montenegro foi realizada somente nos indivíduos que apresentavam lesões suspeitas de LT no momento da investigação, ou naqueles que tinham história pregressa de LT e haviam feito IDR há mais de dois anos. O antígeno usado foi preparado no Laboratório de Ensino e Pesquisa em Análises Clínicas da Universidade Estadual de Maringá (LEPAC/UEM) com a cepa M HOM/BR/ 88/166MJO de Leishmania (Leishmania) amazonensis em salina mertiolatada 1/10.000 (Arraes et al., 1991). Também foi inoculado um controle de salina mertiolatada a 1/10.000. Foram consideradas positivas as reações cujo diâmetro médio foi superior a $6 \mathrm{~mm}$, após 48 a 72 horas.

\section{Pesquisa de Leishmania}

Dos pacientes portadores de lesão cutânea no momento da investigação foi coletado material 
da borda da lesão através de biópsia. O material de biópsia foi utilizado para a confecção de esfregaços por aposição em lâminas, as quais foram fixadas em metanol e coradas pelo método de Giemsa. A seguir, o material de biópsia foi colocado em solução salina fisiológica com $1.000 \mathrm{Ul} / \mathrm{ml}$ de penicilina e $1 \mathrm{mg} / \mathrm{ml}$ de estreptomicina e, posteriormente, triturado e inoculado nas patas posteriores de hamsters. Após o desenvolvimento das lesões, estes animais foram sacrificados e o isolamento da Leishmania foi feito em meio Blood Base Agar (Shaw \& Lainson, 1981), com 10\% de sangue de coelho, total e desfibrinado, contendo $2.000 \mathrm{UI}$ de penicilina e $2 \mathrm{mg}$ de estreptomicina por $\mathrm{ml}$, a $25^{\circ} \mathrm{C}$. A cepa isolada foi enviada ao Instituto Evandro Chagas - Belém - Pará, para identificação.

Reação de imunofluorescência indireta para doença de Chagas

Os soros dos indivíduos com títulos significativos na IFI para Leishmania e sem história de LT foram submetidos a IFI para doença de Chagas conforme Camargo (1966), utilizando-se conjugado antiimunoglobulina total humana-isotiocianato de fluoresceína (Biolab), padronizado conforme Camargo (1973). Os soros foram diluídos em SST a partir de 1/ 20 em razão 2 . Foram considerados significativos títulos iguais ou superiores a 80.

\section{Resultados}

Na Tabela 1, observa-se que, dos 684 indivíduos investigados, 136 (19,9\%) tinham história pregressa de LT ou estavam com LT no momento desta investigação. Na Fazenda Jussara, de 126 indivíduos estudados, 51 (40,5\%) encontravam-se nestas condições. Das seis localidades estudadas, o menor percentual foi encontrado na Fazenda Mururê (6,5\%).

Ainda na Tabela 1, verifica-se que, dos 136 indivíduos com história pregressa de LT ou que apresentavam LT no momento da investigação, em 97 deles foi realizada a IDR, sendo esta positiva em 80 (82,5\%) e negativa em 17 (17,5\%). De 24 indivíduos não foi possível obter os resultados da IDR, pois, ou não compareceram para leitura, ou apresentaram o diâmetro da reação ao controle próximo ao do antígeno, ou a reação não foi realizada. Quinze indivíduos relataram ter apresentado a IDR positiva nos últimos dois anos.

A reação de imunofluorescência indireta foi realizada em 135 indivíduos, sendo positiva em 36 (26,7\%) deles. Dos 548 indivíduos sem história de LT, 22 (4,0\%) foram soro-reagentes na IFI, os quais foram submetidos à IFI para Doença de Chagas e cinco tiveram títulos iguais ou superiores aos encontrados na IFI para LT. Dos 17 indivíduos restantes, 16 (94,1\%) afirmaram residir, há pelo menos três anos, na mesma localidade onde foi realizada a investi-

Tabela 1

Resultados das reações de imunofluorescência indireta (IFI) e intradermorreação de Montenegro (IDR) para leishmaniose tegumentar (LT) realizadas em indivíduos de seis propriedades agrícolas, nos Municípios de J ussara e Terra Boa, Noroeste do Estado do Paraná, em 1992 e 1993.

\begin{tabular}{|c|c|c|c|c|c|c|c|c|c|}
\hline & & & \multicolumn{5}{|c|}{ Localidade } & \multirow[b]{2}{*}{$\begin{array}{l}\text { Fazenda } \\
\text { Mururê }\end{array}$} & \multirow[t]{2}{*}{ Total } \\
\hline & & & $\begin{array}{l}\text { Fazenda } \\
\text { Palmital }\end{array}$ & $\begin{array}{l}\text { Cerâmica } \\
\text { Andirá }\end{array}$ & $\begin{array}{l}\text { Fazenda } \\
\text { J ussara }\end{array}$ & $\begin{array}{l}\text { Fazenda } \\
\text { Lagoa }\end{array}$ & $\begin{array}{l}\text { Destilarias } \\
\text { Melhoramentos }\end{array}$ & & \\
\hline \multirow{4}{*}{\multicolumn{2}{|c|}{ Indivíduos }} & investigados - $n$ & 130 & 47 & 126 & 61 & 106 & 214 & 684 \\
\hline & & c/ história de LT - n & 39 & 8 & 51 & 9 & 15 & 14 & 136 \\
\hline & & c/ história de LT - \% & 30,0 & 17,0 & 40,5 & 14,8 & 14,1 & 6,5 & 19,9 \\
\hline & & s/ história de LT - n & 91 & 39 & 75 & 52 & 91 & 200 & 548 \\
\hline \multirow{7}{*}{$\begin{array}{l}\text { Indivíduos } \\
\text { c/ história } \\
\text { de LT }\end{array}$} & \multirow[t]{4}{*}{ IDR } & realizadas positiva & 24 & 3 & 37 & 4 & 8 & 4 & 80 \\
\hline & & realizadas negativa & 3 & 3 & 5 & 0 & 2 & 4 & 17 \\
\hline & & realizadas $\mathrm{NC/?/NR}$ & 5 & 0 & 4 & 4 & 5 & 6 & 24 \\
\hline & & relatada positiva & 7 & 2 & 5 & 1 & 0 & 0 & 15 \\
\hline & \multirow[t]{3}{*}{$|F|$} & positiva & 5 & 3 & 22 & 2 & 2 & 2 & 36 \\
\hline & & negativa & 34 & 5 & 28 & 7 & 13 & 12 & 99 \\
\hline & & NR & 0 & 0 & 1 & 0 & 0 & 0 & 1 \\
\hline \multirow{2}{*}{$\begin{array}{l}\text { Indivíduos } \\
\text { s/ história } \\
\text { de LT }\end{array}$} & \multirow[t]{2}{*}{ IFI } & positiva & 3 & 5 & 8 & 1 & 2 & 3 & 22 \\
\hline & & negativa & 88 & 34 & 67 & 51 & 89 & 197 & 526 \\
\hline
\end{tabular}

NC - não compareceram para leitura

? - resultado duvidoso (diâmetro da reação semelhante ao do controle)

NR - reação não realizada 
Tabela 2

Distribuição dos indivíduos com história de leishmaniose tegumentar, segundo o sexo e a idade, de seis propriedades agrícolas, nos Municípios de J ussara e Terra Boa, Noroeste do Estado do Paraná, em 1992 e 1993.

\begin{tabular}{cccrr}
\hline \multirow{2}{*}{$\begin{array}{c}\text { Faixa Etária } \\
\text { anos }\end{array}$} & Masculino & Feminino & \multicolumn{2}{c}{ Total } \\
\hline $0-9$ & 4 & 1 & 5 & 3,7 \\
$10-19$ & 16 & 8 & 24 & 17,6 \\
$20-29$ & 19 & 7 & 26 & 19,1 \\
$30-39$ & 25 & 2 & 27 & 19,9 \\
$40-49$ & 16 & 7 & 23 & 16,9 \\
$50-59$ & 14 & 8 & 22 & 16,2 \\
$60-69$ & 9 & 0 & 9 & 6,6 \\
Total & $103(75,7 \%)$ & $33(24,3 \%)$ & 136 & 100,0 \\
\hline
\end{tabular}

gação ou em área rural de municípios vizinhos, considerados endêmicos para LT.

A distribuição dos 136 indivíduos, segundo sexo e idade, que apresentavam história pregressa ou estavam com LT encontra-se na Tabela 2. As faixas etárias desta tabela correspondem às idades dos indivíduos no momento em que se realizou a pesquisa. Destes indivíduos, $103(75,7 \%)$ eram do sexo masculino. Pouca diferença foi observada nos percentuais encontrados entre os indivíduos das faixas etárias de 10 a 59 anos.

De 136 indivíduos com história pregressa, quatro $(2,9 \%)$ apresentavam comprometimento nasobucofaríngeo, três $(2,2 \%)$ relataram ter tido a doença mais de uma vez e 14 (10,3\%) apresentavam lesão no momento da investigação.

Nos 14 indivíduos que tinham lesão, pelo menos um dos testes realizados apresentou-se positivo. Os resultados dos exames realizados encontram-se na Tabela 3. Treze destes indivíduos apresentavam lesão cutânea e o paciente C.P. (registro 249) apresentava comprometimento nasobucofaríngeo. Destes pacientes, a IFI foi realizada em 13, sendo positiva em nove $(69,2 \%)$. De sete obteve-se material de lesão para pesquisa de Leishmania sp. e em quatro o resultado foi positivo. A cepa de Leishmania sp. isolada do paciente H.S.F.F. (registro 178) foi identificada como Leishmania (Viannia) brazi-

Tabela 3

Resultados dos exames realizados nos 14 indivíduos que apresentavam lesão no momento da investigação, de seis propriedades agrícolas, nos Municípios de J ussara e Terra Boa, Noroeste do Estado do Paraná, em 1992 e 1993.

\begin{tabular}{|c|c|c|c|c|c|}
\hline Paciente (registro) & Tempo de evolução da lesão & Tratamento & IDR (mm) & IFI & Microscopia de material de lesão \\
\hline J.B.S. (10) & 5 meses & não & 22,0 & $<20$ & negativa \\
\hline J.S.A. (28) & 4 meses & em tratamento & 17,5 & $<20$ & NR \\
\hline I.R.S. (40) & 3 meses & em tratamento & 19,0 & 40 & NR \\
\hline M.S.A. (43) & 3 meses & em tratamento & 15,0 & $<20$ & NR \\
\hline J.A.S. (51) & 2 meses & não & $?$ & 20 & positiva \\
\hline V.A. (120) & 3 meses & em tratamento & + & 40 & NR \\
\hline H.S.F.F. (178) & 4 meses & em tratamento & 5,0 & 80 & positiva \\
\hline C.P. $(249)$ & 1 ano & em tratamento & + & 40 & NR \\
\hline M.A.B.M. (255) & 3 meses & em tratamento & + & 80 & NR \\
\hline J.C.A. (268) & 1 mês & em tratamento & + & $N R$ & NR \\
\hline A.J.A. (276) & 1 ano e 2 meses & em tratamento & + & 40 & negativa \\
\hline J.S. (445) & 1 mês & não & 15,0 & 80 & positiva \\
\hline V.A.M. (474) & 1,5 meses & não & NR & 80 & negativa \\
\hline P.R.S. (507) & ND & em tratamento & NR & 40 & positiva \\
\hline
\end{tabular}

IFI - Imunofluorescência Indireta

IDR - Intradermorreação de Montenegro

ND - não determinada

NR - não realizada

+ - IDR relatada como positiva

? - resultado duvidoso (diâmetro do controle semelhante ao diâmetro da reação) 
liensis através de anticorpos monoclonais, pelo Dr. J.J. Shaw.

A combinação dos resultados de IDR e IFI realizadas em 122 indivíduos com história pregressa de LT encontra-se na Tabela 4. Dez destes indivíduos relataram ter apresentado IDR positiva num período inferior a dois anos; portanto, não foram submetidos a uma nova reação. De 21 indivíduos, não foi possível obter o resultado por um dos seguintes motivos: ou o paciente não compareceu para a leitura da reação, ou houve reação ao controle de salina mertiolatada em diâmetro próximo ao do antígeno, ou a reação não foi realizada. Dos 91 em que foi possível obter o resultado da IDR, $75(82,4 \%)$ tiveram resultados positivos. Destes 91 indivíduos, 22 (24,2\%) apresentaram títulos significativos de anticorpos pela IFI, dos quais 19 tiveram IDR positivas e três foram negativas.

Dos 19 indivíduos com IDR e IFI positivas, 18 afirmaram ter sido submetidos a tratamento e o tempo decorrido desde a infecção até a investigação variou de oito meses a 45 anos. A pesquisa de anticorpos anti-T. cruzi não foi realizada nestes indivíduos. Dos três indivíduos com IDR negativa e IFI positiva, um não recebeu tratamento e outro afirmou ter tido leishmaniose tegumentar em duas ocasiões.

\section{Discussão}

No Norte do Estado do Paraná, o número de casos notificados de leishmaniose tegumentar tem aumentado nos últimos anos (Teodoro et al., 1988; 1991; Verzignassi et al., 1988; Silveira et al., 1992; 1994; Konolsaisen, 1995, Centro de Epidemiologia - Secretaria de Estado da Saúde do Paraná, informações pessoais), e os Municípios de Jussara e Terra Boa têm se destacado na região noroeste por apresentarem alta endemicidade (Teodoro et al., 1991; Silveira et al., 1994). Tal fato está sendo mostrado neste inquérito, uma vez que 19,9\% dos indivíduos investigados tiveram ou estavam com a doença no momento da investigação. Este percentual pode ser comparado ao relatado por Barretto et al. (1981) em uma região endêmica do Estado da Bahia, onde 155 (31,8\%) de 488 indivíduos recenseados tinham lesões ou cicatrizes de LT.

O encontro de 80 (11,7\%) indivíduos com história de LT e IDR positiva, confirma a endemicidade da LT na área estudada, pois a IDR de Montenegro, segundo Furtado (1980), possui alta sensibilidade (86,4 a 97,5\%), permanecendo positiva, na maioria das vezes, após a cura clínica das lesões. Esta reação pode ser útil como diagnóstico retrospectivo da LT, embora tenham sido relatadas reações cruzadas com outras espécies de Leishmania ou com outras afecções como pênfigo e tuberculose ganglionar (Furtado, 1980).

Percentuais de indivíduos com história pregressa de LT e IDR positiva observados neste trabalho $(82,4 \%)$ assemel ham-se aos resultados (90,8\%) de Barretto et al . (1981), mostrando que a reatividade ao antígeno de Montenegro mantem-se por longos períodos de tempo. Aqueles que não apresentaram reação positiva (17,6\%) podem ter perdido a resposta imunitária ou ter tido lesão que não fosse leishmaniose (Barretto et al., 1981).

\section{Tabela 4}

Distribuição dos resultados da Intradermorreação de Montenegro (IDR) e Imunofluorescência Indireta (IFI) realizadas nos 122 indivíduos com história pregressa de leishmaniose tegumentar, de seis propriedades agrícolas, nos Municípios de J ussara e Terra Boa, Noroeste do Estado do Paraná, em 1992 e 1993.

\begin{tabular}{llllll}
\hline & & & IFI & & Total \\
& & Positiva & Negativa & NR & \\
\hline IDR & Positiva - n & 19 & 55 & 1 & 75 \\
& Positiva - \% & 15,6 & 45,1 & 0,8 & 61,5 \\
& Negativa - n & 3 & 13 & 0 & 16 \\
& Negativa - \% & 2,5 & 10,7 & 0,0 & 13,2 \\
& NC/?/NR - n & 1 & 19 & 1 & 21 \\
& NC/?/NR - \% & 0,8 & 15,5 & 0,8 & 17,1 \\
& Relatada positiva - n & 4 & 6 & 0 & 10 \\
& Relatada positiva - \% & 3,3 & 4,9 & 0,0 & 8,2 \\
& & & & & 122 \\
Total & n & 27 & 93 & 2 & 100,0 \\
& $\%$ & 22,2 & 76,2 & 1,6 & \\
\hline
\end{tabular}

NC - não compareceu para leitura

? - resultado duvidoso (diâmetro do controle semelhante ao diâmetro da reação) NR - reação não realizada 
Dos indivíduos com lesão ativa de leishmaniose tegumentar, encontramos $69,2 \%$ com IFI positiva, enquanto Barretto et al. (1981) encontraram $51,4 \%$. No presente trabalho, foram também encontrados indivíduos com história de LT há mais de oito meses e que ainda apresentavam títulos significativos de anticorpos pela IFI. Segundo Furtado (1980), os títulos de anticorpos detectados pela IFI diminuem ou desaparecem após o tratamento adequado, possibilitando o emprego desta reação no controle da cura clínica da LT; no entanto, Marzochi et al. (1980) também observaram paciente com IFI positiva quatro anos após o tratamento.

Dos indivíduos (22) sem história de LT e com títulos de anticorpos significativos na IFI, cinco apresentaram títulos de anticorpos para doença de Chagas iguais ou superiores aos encontrados para LT. A reação de IFI para LT é grupo-específica, sendo os títulos de anticorpos fluorescentes mais elevados com os antígenos homólogos (Camargo \& Rebonato, 1969; Furtado, 1980). Reações cruzadas entre doença de Chagas e leishmaniose tegumentar têm sido relatadas por vários autores (Camargo, 1966; Guimarães et al., 1974; Furtado, 1980). Os $17(2,5 \%)$ restantes, poderiam ser ou indivíduos sensibilizados por Leishmania sp. devido ao contato permanente com picadas de flebotomíneos, o que, segundo Marzochi et al. (1980), levaria à positividade de testes sorológicos e da intradermorreação de Montenegro, sugerindo manifestações inaparentes da doença, ou falsos resultados positivos, pois a especificidade da técnica de IFI é de 91,9\% (Silveira et al., 1990).

O percentual de indivíduos com comprometimento nasobucofaríngeo (2,9\%) está dentro da freqüência encontrada em outras áreas endêmicas conhecidas e tem diminuído, provavelmente devido ao diagnóstico e tratamento precoce (Marzochi, 1992). Segundo ainda

\section{Agradecimentos}

Ao Dr. J. J. Shaw, Instituto Evandro Chagas, Belém, pela identificação da cepa de Leishmania. Aos técnicos de laboratório do Departamento de Análises Clínicas, Luiz Saraiva Arraes, Sandra Vieira da Silva, João Balduíno Kuhl e Dilma Figueiredo Botter, pelo apoio técnico dado para a realização deste trabalho.
Marzochi (1992), em áreas periurbanas de leishmaniose por L. braziliensis no Rio de Janeiro, as reinfecções são bastante raras. No entanto, o parasita pode persistir e ser isolado de lesões tratadas adequadamente (Schubach et al., 1987).

Nas Fazendas Palmital e Jussara, onde ocorreram as maiores incidências de indivíduos que tiveram leishmaniose, 30,0 e 40,5\% respectivamente, os ambientes domiciliares e peridomiciliares podem ter oferecido condições mais propícias para a ocorrência do ciclo de transmissão de Leishmania, pois, além de cães infectados (Lonardoni et al., 1993), a quantidade de flebotomíneos capturados anteriormente nestas localidades foi bastante elevada (Teodoro et al., 1993; 1994).

\section{Conclusões}

Os resultados encontrados comprovam a endemicidade da leishmaniose tegumentar na região Noroeste do Estado do Paraná, uma vez que $19,9 \%$ dos indivíduos estudados tiveram ou estavam com LT.

Indivíduos sem história de leishmaniose tegumentar em área endêmica podem apresentar títulos de anticorpos anti-Leishmania, sugerindo a ocorrência de infecções inaparentes.

O encontro de indivíduos com história de leishmaniose tegumentar há mais de oito meses e títulos de anticorpos anti-Leishmania mostram que estes anticorpos podem persistir mesmo após tratamento e cicatrização da lesão, por tempo relativamente longo, sugerindo a persistência do parasita mesmo após o tratamento e, portanto, a possibilidade de recidivas.

A endemia não é recente na área, pois, entre as pessoas investigadas e com história pregressa da doença, ocorreu um caso há 20 anos em indivíduo residente há 27 na área estudada.

\section{Referências}

ARRAES, S. M. A. A.; SILVEIRA, T. G. V.; LONARDONI, M. V. C.; RAMOS, M.; BERTOLINI, D. A. \& DIAS, M. L. G. G., 1991. Avaliação da intradermorreação de Montenegro: comparação entre dois antígenos de diferentes procedências. Revista Unimar, 13:5-10.

BARRETTO, A. C.; CUBA, C. A. C.; MARSDEN, P. D.; VEXANAT, J. A. \& BELDER, M. D., 1981. Características epidemiológicas da leishmaniose tegumentar americana em uma região endêmica do Estado da Bahia, Brasil I. Leishmaniose humana. Boletin de la Oficina Sanitaria Panamericana, 90:415-423. 
CAM ARGO, M. E., 1966. Fluorescent antibody test for the serodiagnosis of american trypanosomiasis. Technical modification employing culture forms of Trypanosoma cruzi in a slide test. Revista do Instituto de Medicina Tropical deSão Paulo, 8:227-234.

CAMARGO, M. E. \& REBONATO, C., 1969. Cross-reactivity in fluorescence tests for Trypanosoma and Leishmania antibodies. American Journal of Tropical Medicine and Hygiene, 18:500-505.

CAM ARGO, M. E., 1973. Introdução às Técnicas de Imunofluorescência. São Paulo: Instituto de Medicina Tropical de São Paulo.

COUTINHO, S. G.; MARZOCHI, M. C. A.; SOUZA, W. J. S. \& AMENDOEIRA, M. R. R., 1981. Leishmaniose tegumentar americana. Jornal Brasileiro de Medicina, 41:104-118

FNS (FUNDAÇÃO NACIONAL DE SAÚDE), 1993. Guia de Controle da Leishmaniose Tegumentar Americana. Brasília: Ministério da Saúde.

FURTADO, T., 1980. Critérios para o diagnóstico da leishmaniose tegumentar americana. Anais Brasileiros de Dermatologia, 52:81-86.

GRIMALDI JR., G.; TESH, R. B. \& MCMAHON-PRATT, D., 1989. A review of the geografic distribution and epidemiology of leishmaniasis in the new world. American Journal of Tropical Medicineand Hygiene, 41:687-725.

GUIMARÃES, M. C. S.; GIOVANNINI, V. L. \& CAMARGO, M. E., 1974. Antigenic standardization from mucocutaneous leishmaniasis immunofluorescence test. Revista do Instituto de Medicina Tropical deSão Paulo, 16:145-148.

GUIMARÃES, M. C. S.; CELESTE, B. J.; CAM ARGO, M. E. \& DINIZ, J. M. P., 1983. Seroepidemiology of cutaneous leishmaniasis from Ribeira do I guape Valley. IgM and IgG antibodies detected by means of an immunoenzymatic assay (ELISA). Revista do Instituto de Medicina Tropical de São Paulo, 25:108-112.

LONARDONI, M. V. C.; TEODORO, U.; ARRAES, S. M. A. A.; SILVEIRA, T. G. V.; BERTOLINI, D. A.; ISHIKAWA, E. A. Y. \& SHAW, J. J., 1993. Nota sobre leishmaniose canina no noroeste do Estado do Paraná, sul do Brasil. Revista deSaúdePública, 27:378-379.

MARZOCHI, M. C. A.; COUTINHO, S. G.; SABROZA, P. C. \& SOUZA, W. J. S., 1980. Reação de imunofluorescência indireta e intradermorreação para leishmaniose tegumentar americana em moradores na área de Jacarepaguá (Rio de Janeiro). Estudo comparativo dos resultados observados em 1974 e 1978. Revista do Instituto de Medicina Tropical deSão Paulo, 22:149-155.

MARZOCHI, M. C. A., 1992. Leishmanioses no Brasil. As leishmanioses tegumentares. Jornal Brasileiro de Medicina, 63:82-104.

SCHUBACH, A.; MARZOCHI, M.; ARAÚJO, M. L. \& CONCEIÇÃO, N. F., 1987. Healed lesion of cutaneous leishmaniasis - a positive culture for Leishmania sp. the scar tissue years after cure. Memórias do Instituto Oswaldo Cruz, 82:187.

SHAW, J. J. \& LAINSON, R., 1981. The "in vitro" cultivation of members of the Leishmania braziliensis complex. Transactions of the Royal Society of Tropical Medicine and Hygiene, 75:127.
SILVEIRA, T. G. V.; ARRAES, S. M. A. A.; PEREIRA, D. S.; LONARDONI, M. V. C.; DIAS, M. L. G. G.; RAMOS, M.; BERTOLINI, D. A.; FRESSATTI, R. \& MISUTA, N. M., 1990. Avaliação da reação de imunofluorescência indireta para leishmaniose tegumentar americana em pacientes da região noroeste do Estado do Paraná - Brasil. Revista Unimar, 12:177188.

SILVEIRA, T. G. V.; LONARDONI, M. V. C.; ARRAES, S. M. A. A.; BERTOLINI, D. A.; RAMOS, M. \& TEODORO, U., 1992. Leishmaniose tegumentar americana - aspectos epidemiológicos no norte do estado do Paraná - Brasil. Resumos do IV Encontro Científico da Universidade Estadual de Maringá, Maringá, Paraná (mimeo.)

SI LVEIRA, T. G. V.; LONARDONI, M. V. C.; ARRAES, S. M. A. A.; BERTOLINI, D. A.; RAMOS, M . \& TEODORO, U., 1993. Aspectos epidemiológicos da leishmaniose tegumentar americana na região noroeste do estado do Paraná - Brasil. Resumos do II Congresso de Farmácia eAnálises Clínicas de Maringá. Maringá, Paraná (mimeo.).

SILVEIRA, T. G. V.; TEODORO, U.; LONARDONI, M. V. C.; GUILHERME, A. L. F.; TOLEDO, M. J. O.; RAM OS, M.; ARRAES, S. M. A. A.; BERTOLINI, D. A.; SPINOSA, R. P. \& BARBOSA, O. C., 1994. Investigação epidemiológica da leishmaniose tegumentar em área endêmica no estado do Paraná, sul do Brasil. Memórias do Instituto Oswaldo Cruz, 89:181.

TEODORO, U.; MISUTA, N. M.; PEREIRA, D. S.; VERZIGNASSI, T. G.; FERREIRA, M. E. M. C.; DIAS, M. L. G. G.; ARISTIDES, S. M. A. \& FRESSATTI, R., 1988. Leishmaniose tegumentar americana: flebotomíneos de área de transmissão no norte do Paraná - Brasil. Ciência e Cultura, 40:885.

TEODORO, U.; SPINOSA, R. P.; LA SALVIA FILHO, V.; GUILHERME, A. L. F.; LIMA, A. P.; JUNQUEIRA, G. M. B.; MISUTA, N. M.; NERILO SOBRINHO, A \& LIMA, E. M., 1991. Da necessidade de se adotar e divulgar esquemas terapêuticos para tratamento de leishmaniose tegumentar no Paraná. Revista do Instituto de Medicina Tropical de São Paulo, 33:199-204.

TEODORO, U.; LA SALVIA FILHO, V.; LIMA, E. M.; SPINOSA, R. P.; BARBOSA, O. C.; FERREIRA, M. E. M. C. \& LONARDONI, M. V. C., 1993. Observações sobre o comportamento de flebotomíneos em ecótopos florestais e extraflorestais em área endêmica de leishmaniose tegumentar americana no norte do Estado do Paraná - Brasil. Revista de SaúdePública, 27:242-249.

TEODORO, U.; KUHL, J. B.; BARBOSA, O. C.; SOCCOL, V. T.; LOZOVEI, A. L.; SILVEIRA, T. G. V. \& ROBERTO, A. C. B. S., 1994. O saneamento ambiental e a organização peridomiciliar como medidas auxiliares no controle de flebotomíneos, no estado do Paraná, Sul do Brasil. Memórias do Instituto Oswaldo Cruz, 89:206.

VERZIGNASSI, T. G.; PEREIRA, D. S.; TEODORO, U.; MISUTA, N. M; DIAS, M. L. G. G.; FERREIRA, M. E. M. C.; FRESSATTI, R. \& ARISTIDES, S. M. A., 1988. Leishmaniose tegumentar americana: aspectos epidemiológicos no norte do Paraná Brasil. Ciência e Cultura, 40:884. 